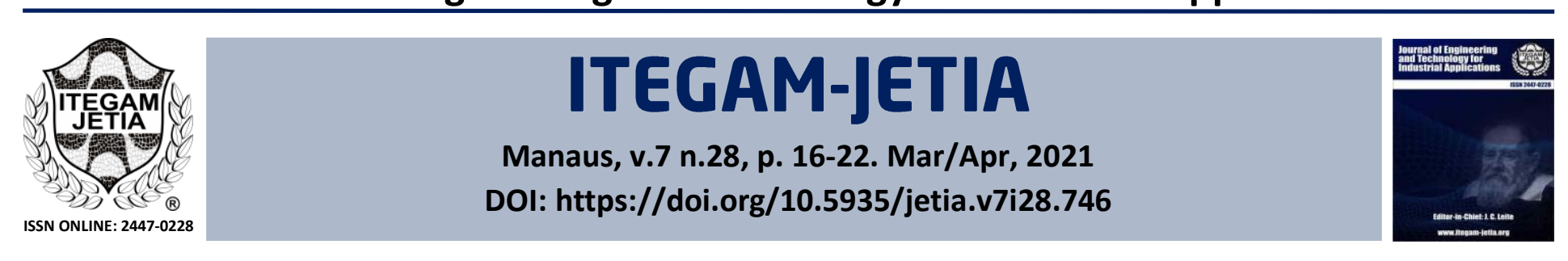

\title{
PRO-ATHLETE: A GUIDE SYSTEM FOR VISUALLY IMPAIRED ATHLETES IN OLYMPIC TRACK RACE
}

\author{
André Machado ${ }^{1}$ and Celso Carvalho*2 \\ ${ }^{1,2}$ Graduate Program in Electrical Engineering (PPGEE), Federal University of Amazonas (UFAM), Manaus, Amazonas, Brazil.
}

${ }^{1}$ http://orcid.org/0000-0002-3057-6356 이, ${ }^{2}$ https://orcid.org/0000-0002-7378-8893 (i)

Email: andredias_m@hotmail.com,*ccarvalho_@ufam.edu.br

\begin{tabular}{|c|c|}
\hline ARTICLE INFO & ABSTRACT \\
\hline Received: March $28^{\text {th }}, 2021$ & autonomy in their daily activities. An opportunity for improvement appears in the athletics \\
\hline Published: April 30 $0^{\text {th }}, 2021$ & $\begin{array}{l}\text { have autonomy and runs tied by rope to a guide and may have several problems of } \\
\text { disqualification and reduced performance due to the necessary synchronization between }\end{array}$ \\
\hline Keywords: & athlete and guide. In this context, in this article we developed a hardware and software \\
\hline Language Code, & race. The prototype was tested in simulated athletic races, showing good results, with \\
\hline Wireless Networks. & commands and stimuli being well understood and interpreted by visually impaired athletes. \\
\hline
\end{tabular}

Copyright (C2016 by authors and Galileo Institute of Technology and Education of the Amazon (ITEGAM). This work is licensed under the Creative Commons Attribution International License (CC BY 4.0).

\section{INTRODUCTION}

Sports are an important part of human expression and culture. Through sports, athletes can achieve the best performance of body, breaking records of speed, endurance, distance, and precision. It is noticed that human ingenuity has its principle in the use of techniques that are becoming more sophisticated for the well-being of human being [1-3]. In this sense, we reflect how important technologies are in our activities, including sports.

Currently there is a range of technological devices to guide the athlete to his best performance: be it in training, through a balanced diet with supplements, in clothes with fabrics suitable for each type of sport, in the use of technological shoes, various accessories, among others. In para-athletics practiced by people with visual needs, there is a need to overcome some limitations during the para-athletic race accompanied by guides. In this sport, failures happen, the most common being caused by inefficient communication and the need for synchronization between the athlete and the guide. The so-called "assistive technologies" aim to generate better quality of life and well-being for people with disabilities, in this case, visual impairments. In this context, wireless communication technologies, computing and hardware that generate vibration commands can be used to guide the visually impaired in an Olympic track race. Most of the existing research uses assistive technologies such as, for example, the electronic cane to guide the visually impaired people on the move in everyday life (e.g., streets, schools, closed environments). There are few works that apply assistive technologies in the scenario of visually impaired athletes. Among these works, some need complex infrastructure installations on the track [4]. Others use voice commands transmitted by radio, which ends up creating an extensive linguistic vocabulary, not guaranteeing the correct understanding of commands by the athlete [5]. There are also works that use discrete vocabulary, (ex: left and right command), [6], however limited. This article works in athletics running track scenarios, where each runner carries a hardware and software prototype composed of three wearable devices ( 02 bracelets and 01 belt) that guide the runner during an Olympic trace race through vibration. Unlike the works found in the literature, the prototype of this article does not use hardware technologies with prior installation on the track. In addition, this work proposes a vocabulary of linguistic codes implemented through vibrating stimuli that guarantee greater autonomy to the athlete. (ex: command informing that competing athletes are in proximity). he general objective of this article is to conceive, implement and validate a software and hardware system that implements a language code applicable to vibrating devices to guide visually 
impaired athletes in Olympic track races. To present these subjects, this article is divided into the following subsections. Section II of Theoretical background presents basic theories for understanding the subject of the article; Section III of related works presents recent research on the researched subject; Section IV of the proposed solution presents the architecture and system developed; Section V presents results and performance assessment; and Section VI presents conclusion and future works.

\section{THEORETICAL BACKGROUND}

Sensory deficiency is the failure to recognize information by recipients of a specific sensory channel, for example, vision [7]. When there is a deprivation of some sensory modality, the person can use methods to provide sensory replacement [8]. Sensory substitution refers to the ability of the human mind to adapt the functionalities of another sensory modality [7]. Visual impairment directly influences communication [9], but there are methods, such as Braille used for sensory replacement to help in the reading process [10]. In the Braille example, touch is stimulated to transmit information. However, stimulation can be through repetitive mechanical stimulation mechanisms, for example vibrating [11]. In particular, the analysis of the vibrating or tactile sensitivity can be performed based on the skin's discriminative response, in which a user can distinguish one stimulus from others, depending on the characteristics of the stimulus (e.g., vibration frequency).

The most used sense as a sensorial substitute to provide visual feedback is touch, even if it presents perceptual limits when compared to the visual modality, since the tactile resolution is three times lower than the visual one [12]. Even so, it is possible through touch to meet the needs of proprioception, defined as the identification of objects and communication [13]. For a user to understand vibrating commands it is necessary to have a language (e.g., Portuguese language) and a code (e.g., Morse code). In this article, we created a language code for communication between vibrating devices and a visually impaired athlete, aiming to guide the athlete in training and running events on the track. In order to create a code, it was necessary to perform tests to measure the amount of energy perceived from the user's sensory system and, among these methods, the following stand out [14]: i) differential threshold method, in which a standard stimulus is used and, in then, the intensity of this stimulus is increased or decreased, in order to identify the intensity, in which there is minimal distinction between one stimulus and another; ii) method of constant stimuli in which two or more stimuli are compared using a standard stimulus and comparison stimuli, based on discrete and successive variations; Both methods were used to generate stimuli and pass information during the race to the athlete, as well as to validate the locations of the body and the perception of different stimuli, defining the positioning, in the user, of the devices for sending the linguistic code to the athlete.

\section{RELATED WORKS}

The work [6], one of the closest to our, consists of a device to guide blindfolded people, or visually impaired people to leave a maze by means of a remote control and using vibrating stimuli to inform the direction to be taken. The device was tested on 16 people, with commands given by an operator, who observes the path inside the labyrinth.

The work of [15] presents a system developed to assist the visually impaired in closed environments with objects making it difficult to pass. It also uses vibrating stimuli to communicate with the user, but it is only used in an environment previously processed by the image recognition system, serving only to inform obstacles ahead.

The work of [16] developed a system to guide visually impaired athletes on an athletics track, through the sound of the rotors of a drone that is guided by an operator. A deficiency of this system is that, regardless of the number of available drones, the system could only guide a single athlete once the sound stimuli given to an athlete influence the other athletes around him.

The work of [17] developed a system to guide visually impaired athletes in marathons through equipment that creates electromagnetic waves coupled to a car that moves in front of the athlete, guiding him. However, this is a system that would only be used for the marathon modality and even so it has limitations due to the congestion that could be caused if each athlete used a guide vehicle.

This article aims to present a system capable to guide up to 4 visually impaired athletes in track racing, (one in every 2 tracks.) What can be seen in the related works is that they have developed solutions capable of guiding blindfolded people in environments other than Olympic track racing [4][6][15][16]. Another difference is that the related works evaluated their proposals using blindfolds [6][15] or blind people not Olympic Athlete [4][16]. Our proposal was evaluated using 5 track and field athletes. Other differences between the present proposal and those of the highlighted works are shown in Table 1.

Table 1: Related works.

\begin{tabular}{|c|c|c|c|c|}
\hline Title & Environment & Stimulus/ actuator & Localization & $\begin{array}{c}\text { \# People } \\
\text { Tested } \\
\end{array}$ \\
\hline$[4]$ & Street race & Vibration/engine & Electromagnetic & $\begin{array}{l}1 \text { blind people not } \\
\text { Olympic athlete }\end{array}$ \\
\hline [6] & $\begin{array}{l}\text { Indoor } \\
\text { (Room with } \\
\text { obstacles) }\end{array}$ & Vibration/ engine & Remote commands & 16 (Blindfolded people) \\
\hline$[15]$ & $\begin{array}{l}\text { Indoor } \\
\text { (Room with } \\
\text { obstacles) }\end{array}$ & Vibration/ engine & $\begin{array}{l}\text { Bluetooth e } \\
\text { Kinect }\end{array}$ & 5 (Blindfolded people) \\
\hline [16] & $\begin{array}{l}\text { Street race } \\
\text { (Marathon) }\end{array}$ & Rotor sound/sound & There is not & $\begin{array}{l}2 \text { blind people not } \\
\text { Olympic athletes }\end{array}$ \\
\hline This work & Athletics track & Vibration/ engine & $\begin{array}{l}\text { GPS (proposed only in architecture } \\
\text { and to be implemented in future work) } \\
\text { Remote commands (implemented) }\end{array}$ & 5 blind athletes \\
\hline
\end{tabular}

Source: Authors, (2021). 


\section{PROPOSED SOLUTIONS}

The general architecture of the guide system for Olympic races in shown in Figure 1. The system works with a guide of an athlete with visual impairment, operating a smartphone to remotely pass commands to the athlete to guide him during an Olympic racetrack. The commands given by the guide reach the athlete in the form of vibrating stimuli, passed on to the athlete through a vibrating device, that form a set of commands or language code.

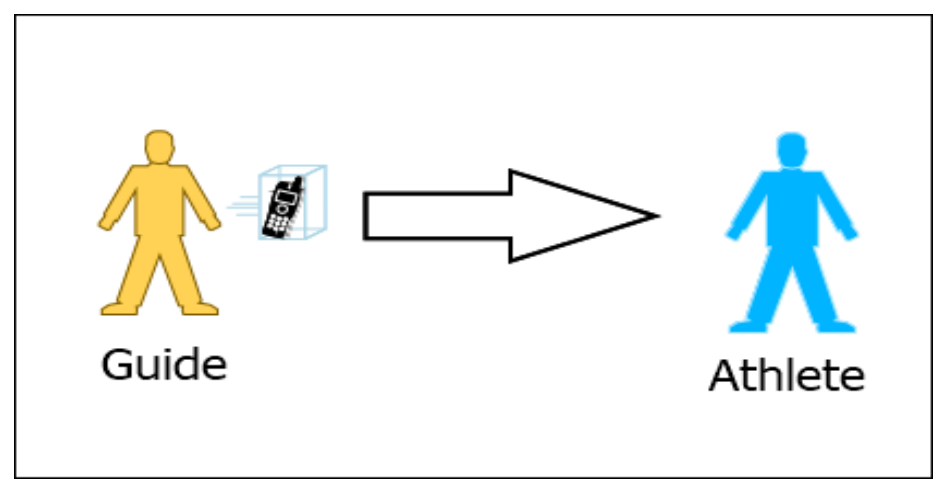

Figure 1: General architecture of the language code system Source: Authors, (2021).

The development of the prototype followed the procedure specified in Figure 2. In Figure 2, block 1 the prototype started with the development a questionnaire to identify the main commands given by the guides who accompany visually impaired athletes in the Olympic races. The activities started with interviews carried out to identify the needs of the visually impaired athlete and finished with validation of the developed prototype, through tests with athletes. We initially collected information to create the linguistic code. For this, we researched the reality of the visually impaired athletes and professionals trained in physical education (PE) knowledge area through a questionnaire, which we call "Semistructured questionnaire for guides and athletes". When using this type of tool, there are no precise rules or strict methods to be followed, depending more on the researcher's intuition and experience. According to [5], the questionnaire may have equal questions and in the same order for all people surveyed and the answers can be open, that is, without alternatives or closed, with fixed alternatives.

The interviews can be unsystematic, with spontaneous questions and answers. Attention is drawn to the fact that interviews and questionnaires are helpful and should only be used when the researcher does not obtain answers from other sources, as was the case with this research. It was from this understanding that a semi-structured questionnaire was produced in the research of this article, with closed and open questions and aimed at guides and visually impaired athletes. The questionnaire contained 14 questions as shown in Table 2.

Table 2: Interview questions to athletes.

a) At what point of the race does the guide transmit the main information to the athlete?

\begin{tabular}{|l|l|l} 
before & during & after
\end{tabular}

First, how is the following information passed on to the athlete? Then assign a grade (1-worst to 5-best) regarding the way the command is passed to the athlete

b) Positioning on the track start block

\begin{tabular}{|l|r|c|c|c|}
\multicolumn{3}{|c|}{ Voice } & \multicolumn{3}{c|}{ Cord } \\
\hline 1 & 2 & 3 & 4 & 5 \\
\hline
\end{tabular}

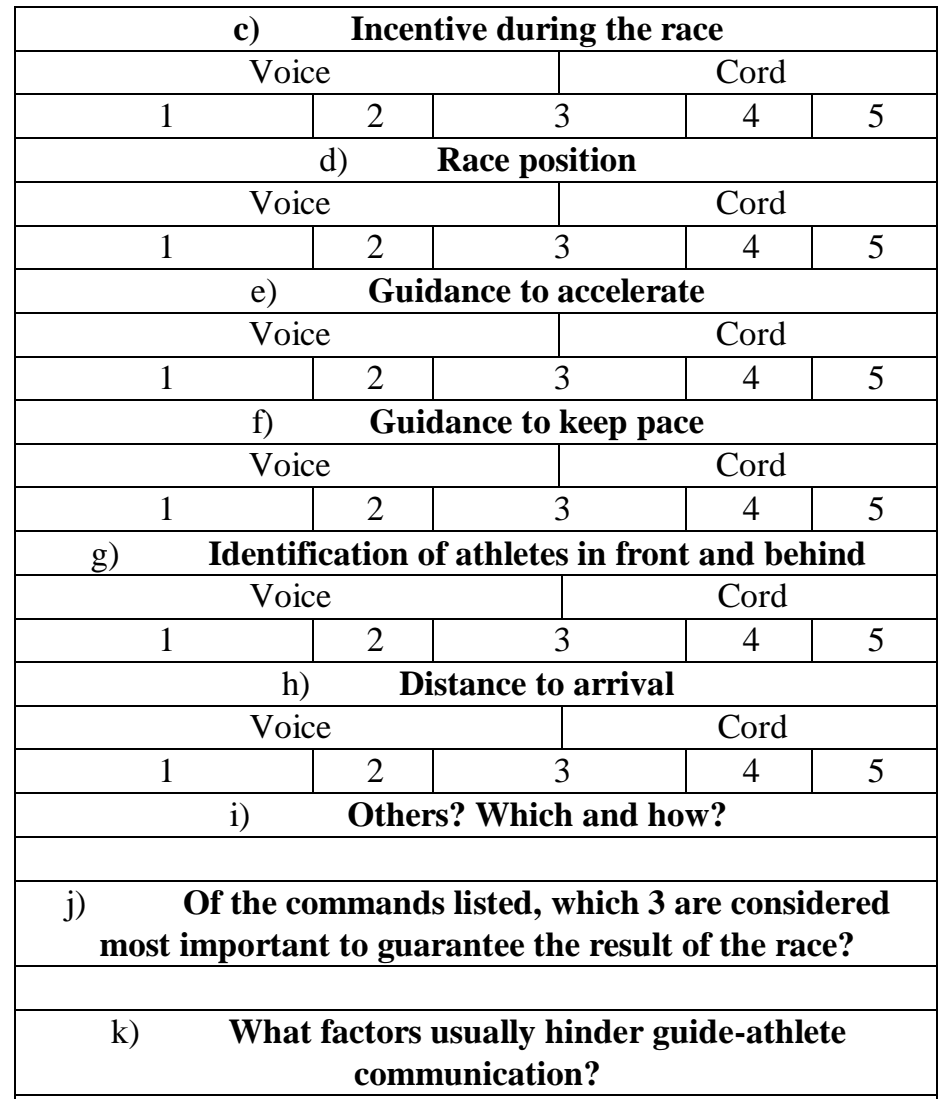

1) What do you think could be done to improve?

m) Do you think a guidance device could improve athletes' performance during the race?

\begin{tabular}{|c|c|c|}
\hline yes & no & I do not know \\
\hline $\mathrm{n})$ & What kind of information or command would \\
grow to the device and which today is not informed by the \\
guide?
\end{tabular}

Source: Authors, (2021).

The first questions were used to understand what kind of commands the guides transmitted to athletes before, during and after the race. From these initial questions, it was defined that the linguistic code would only deal with commands transmitted during the race, the main ones identified by the 27 interviewees were: i) Position of the athlete in the race; ii) distance to arrival; iii) command accelerate and danger. Then, the questions were used to understand how the information was passed from the guide to the athlete, via a cord tied to the two or via voice command, and to assess the quality of the information passed by each of the commands. With the answers, it was found that the voice commands passed by the guides and respective quality scores of the information passed on, from 1 to 5 , with 5 being the best score, were scored by the athletes as follows: i) orientation to accelerate (5); ii) current position (5); iii) guidance to keep pace (5); iv) approaching opponents (3); v) distance to complete the race (3). The only command transmitted by the cord and its respective note was the positioning of the athlete on the track with a score of (5). The interviewees were also asked if there was any factor that would impair voice communication. In response, 24 of the 27 participants said yes, and the three most answered reasons were: crowd noise, traffic noise and voice commands from other guides to their athletes. 


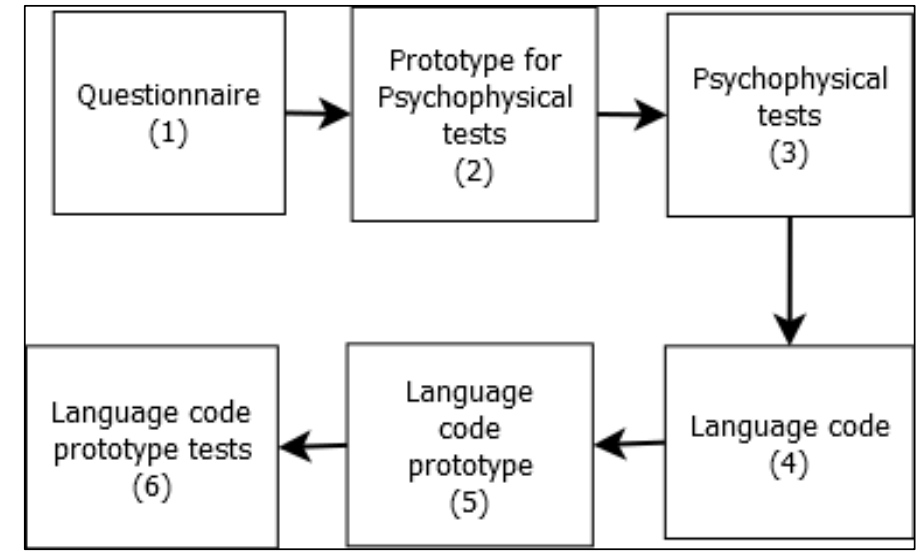

Figure 2: Prototype development procedure. Source: Authors, (2021).

As shown in Figure 2 block 2, a prototype for psychophysical tests was built, whose function was to identify the form and intensity of vibrating stimuli application so that it was possible to pass commands to athletes during the race. The prototype uses an ESP-32 module [18] to which, using its GPIO (General Purpose Input Output Interface) interfaces, were wired connected to 02 bracelets, with 01 vibrating motor in each, positioned on the athletes' wrists and an elastic strap, positioned at athlete's chest, and containing vibrating motors on the athlete's chest and back. More details about the bracelet and elastic strap will be presented in the next section. In the ESP-32 module, a program was developed to control the vibration intensity of the 02 vibrating bracelets and 02 vibrating motors positioned on athlete's chest and back.

Then, Figure 2 block 3, psychophysical tests were carried out using the vibrating prototype of block 2 . The constant stimulus method was applied to verify from which vibration power value it was possible to notice the difference in vibration intensity between the bracelets 1 and 2, with a constant vibration stimulus being applied to bracelet 1 and, a variable vibration being applied to bracelet 2 at the same time. The results of the constant stimulus method evaluation are shown in Table 3 where we can see in the last line that from a vibration frequency difference of $10 \mathrm{~Hz}$, it was possible to perceive the difference in vibration between bracelets 1 and 2.

Then, the differential threshold method was used to identify combinations of vibration frequencies, with differences of $10 \mathrm{~Hz}$, which could be perceived by users. The results of this test are presented in Table 4 where we noticed that the users of the system were able to perceive reduction, increase or if there was no difference between the vibration stimuli of bracelets 1 and 2, with the stimuli having a difference of at least $10 \mathrm{~Hz}$.

Table III. Constant stimulus method.

\begin{tabular}{|c|c|c|}
\hline $\begin{array}{l}\text { Vibrating frequency of } \\
\text { bracelet 1(Hz) }\end{array}$ & $\begin{array}{l}\text { Vibrating frequency of } \\
\text { bracelet 2(Hz) }\end{array}$ & $\begin{array}{l}\text { Users' perception of } \\
\text { vibration frequencies }\end{array}$ \\
\hline 135 & 136 & no difference \\
\hline 135 & 137 & no difference \\
\hline 135 & 138 & no difference \\
\hline 135 & 139 & no difference \\
\hline 135 & 140 & no difference \\
\hline 135 & 141 & no difference \\
\hline 135 & 142 & no difference \\
\hline 135 & 143 & no difference \\
\hline 135 & 144 & no difference \\
\hline 135 & 145 & perceived difference \\
\hline
\end{tabular}

Source: Authors, (2021).

Table IV. Differential threshold method.

\begin{tabular}{|c|c|l|}
\hline $\begin{array}{l}\text { Vibrating frequency } \\
\text { of bracelet 1 (Hz) }\end{array}$ & $\begin{array}{l}\text { Vibrating frequency } \\
\text { of bracelet 2 }(\mathrm{Hz})\end{array}$ & $\begin{array}{l}\text { Users' perception of vibration } \\
\text { frequencies }\end{array}$ \\
\hline 135 & 140 & Higher vibrating power \\
\hline 150 & 140 & Lower vibrating power \\
\hline 135 & 135 & Equal vibrating power \\
\hline 135 & 160 & Higher vibrating power \\
\hline
\end{tabular}

Source: Authors, (2021).

Based on the analysis of the developed questionnaire (Figure 1, block 1) and the results of psychophysical tests (Figure 1, block 3), we created the language code of Table V (Figure 2, block 4), which was evaluated by performing tests by using the language code prototype (Figure 2, block 5) on each individual athlete and, subsequently, validated in a test environment by accomplishing the language code prototype tests of Figure 2, block 6.

Table V. Language code.

\begin{tabular}{|l|l|}
\hline \multicolumn{1}{|c|}{ Command } & \multicolumn{1}{c|}{ Meaning } \\
\hline (1) Vibrate left bracelet & Smoothly turn left \\
\hline (2) Vibrate right bracelet & Smoothly turn right \\
\hline (3) Do not vibrate & Move forward \\
\hline (4) Vibrate in the front with increasing power & $\begin{array}{l}\text { Approaching the athlete } \\
\text { ahead }\end{array}$ \\
\hline (5) Vibrate in the back with increasing power & $\begin{array}{l}\text { Athlete from behind } \\
\text { approaching }\end{array}$ \\
\hline (6) Vibrate in the front with decreasing power & $\begin{array}{l}\text { Front athlete moving } \\
\text { away }\end{array}$ \\
\hline (7) Vibrate in the back with decreasing power & $\begin{array}{l}\text { Distancing from the back } \\
\text { athlete }\end{array}$ \\
\hline $\begin{array}{l}\text { (8) Vibrate the 4 engines simultaneously (01 } \\
\text { engine of each bracelet and 02 engines, 01 in } \\
\text { front and one at the back of the belt) }\end{array}$ & $\begin{array}{l}\text { Athlete advanced another } \\
100 \text { meters }\end{array}$ \\
\hline
\end{tabular}

Source: Authors, (2021).

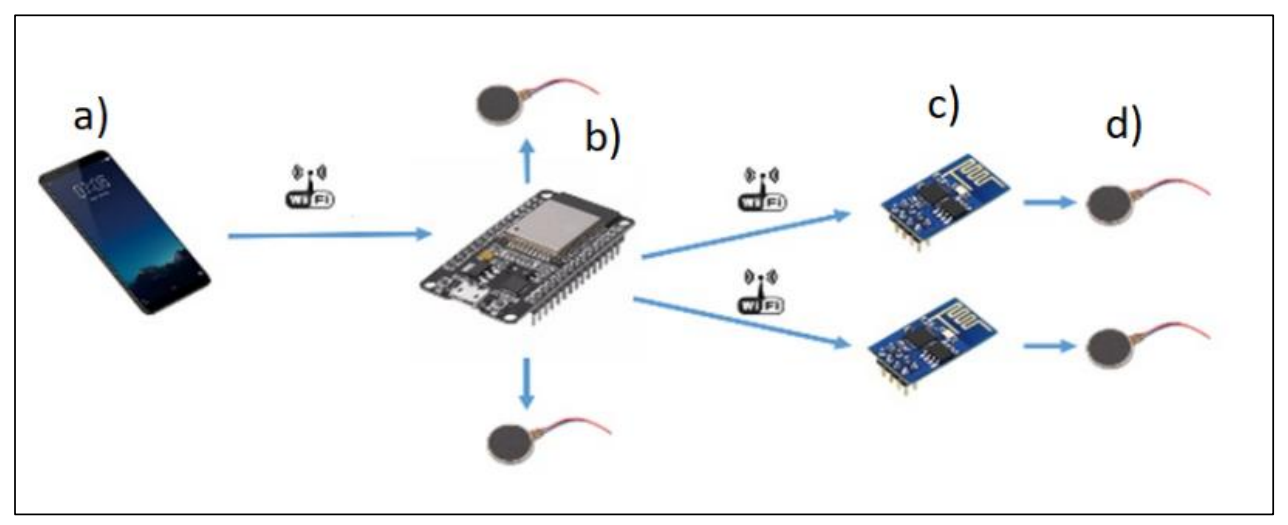

Figure 3: Language code prototype.

Source: Authors, (2021). 
After the development of the linguistic code system, tests were applied in a testing environment. In the tests, we evaluated the language code and the developed language code prototype (Figure 3) through commands sent by a smartphone, checking if the athlete's response was consistent with the command. In the testing environment, a visually impaired athlete moved from the start point to the end point of the $400 \mathrm{~m}$ racetrack, performing one complete lap on an athletics track.

\section{IV.1 LANGUAGE CODE PROTOTYPE}

The developed language code prototype (Figure 3) is composed of: (a) smartphone responsible for sending vibration commands to a set of 4 vibracall motors; (b) an ESP32 microcontroller equipped with Wi-Fi communication, responsible for receiving commands from the smartphone and, forwarding the commands, via wired communication, to the motors located on the front and rear of an elastic strap positioned around the athletes' chest, as well as send, via Wi-Fi communication, commands for the motors of each bracelet, left and right, (c) two ESP01 microcontrollers equipped with Wi-Fi communication, connected each ESP01 to a vibracall engine, which vibrate when receiving commands (ex: turn left or right). The ESP01 microcontroller was chosen because it had the necessary dimension to be placed inside a specially developed bracelet; (d) 4 vibracall type motors.

The vibrating bracelets, Figure 4, positioned one on each athlete's wrist, are composed of an ESP01 microcontroller and a circuit board developed to couple a battery to the vibrating motor, as shown in Figure 5. They also have an enclosure built in a 3D printer to protect each one of circuits / devices. The design of the enclosure was designed to allow it to fit on a watch strap and still fit inside the enclosure an ESP01 microcontroller, a developed circuit board, a vibrating motor, and a battery.

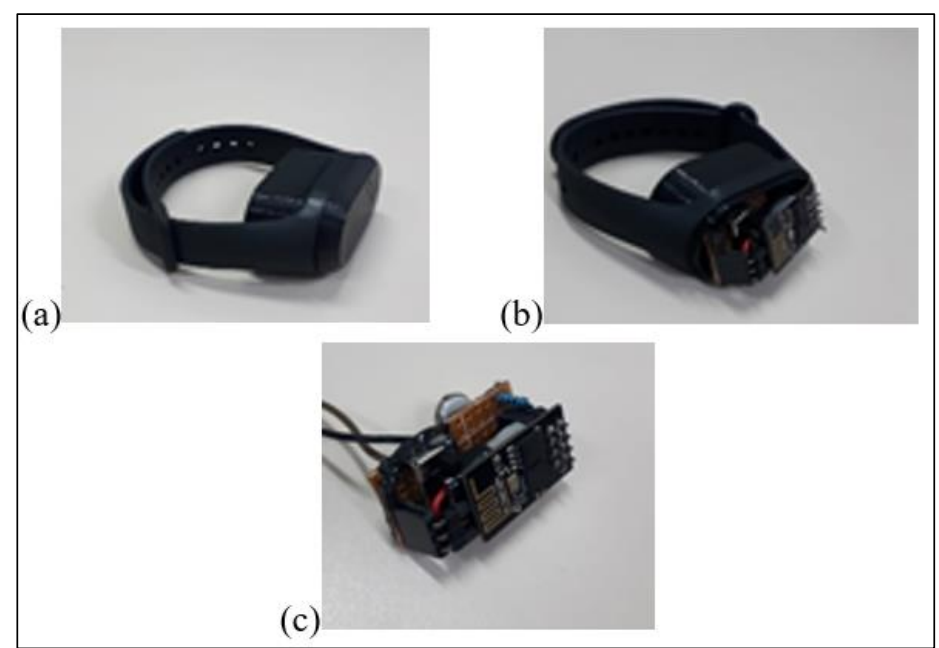

Figure 4: Vibrating bracelets. (a) closed bracelet; (b) bracelet with the apparent internal circuit; (c) circuit board that connects ESP01, battery and motor.

Source: Authors, (2021).

In addition to the bracelets, 2 more points of the body were defined, being the back and chest, to send vibrating commands to athletes during athletics competitions. We also use a smartphone that transmits, via Wi-Fi, commands to the ESP32 microcontroller informing the location (left bracelet, right bracelet, front engine chest or back engine - back) and vibration pattern, to the microcontroller to pass on the linguistic code information to the athlete.

When a command sent by the smartphone, required the activation of the vibrating motors on the athlete's back or chest, the ESP32 itself was responsible for driving the correct motor by wire, according to Table 1 of commands. When a command was directed to one of the vibrating bracelets, the ESP32 module forwarded, via $\mathrm{Wi}-\mathrm{Fi}$, the command to one of the ESP01 modules located on the corresponding wrist. The vibrating devices implemented the language code with the function of guiding the athlete on the athletics track. As can be seen in Figure 3, the ESP32 module was connected to the vibrating motors using two wired connection outputs.

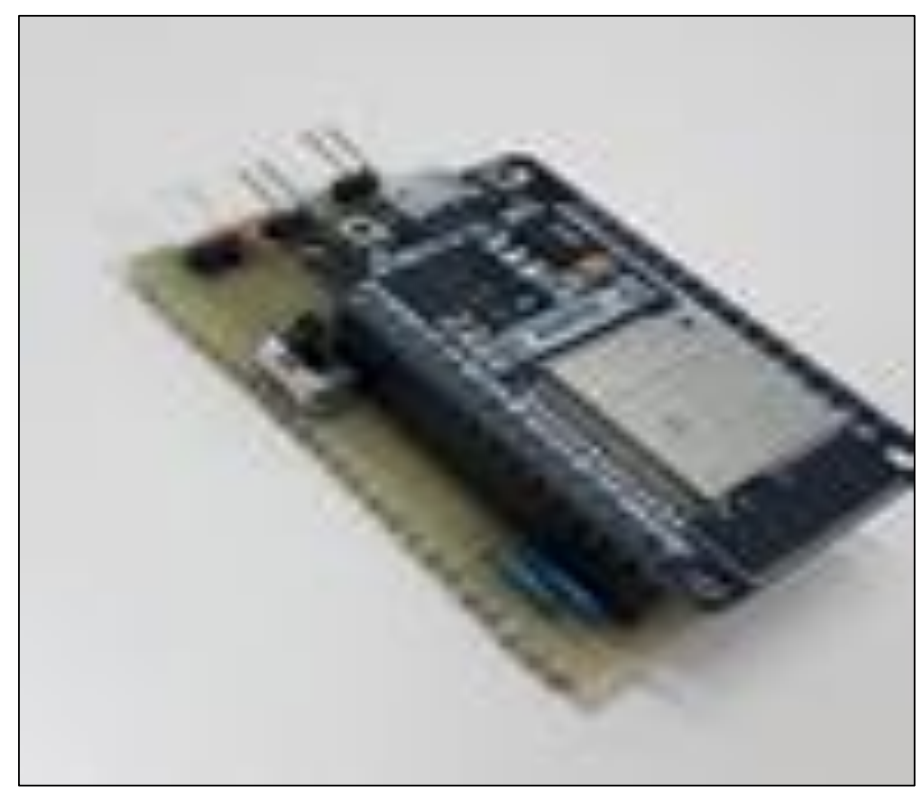

Figure 5: Circuit board developed to connect ESP32 microcontroller and vibrating motors via wired connection. Source: Authors, (2021).

In addition, we developed an embedded code in the ESP32 microcontroller, which was used to receive the information transmitted by the cell phone and forward the commands to activate the correct vibrating device, located on one of the arms, back or chest.

\section{RESULTS AND PERFORMANCE ASSESSMENT}

Android smartphone software was developed to validate the developed linguistic code. This software was used to manually pass information over a wireless network to the athlete during the tests of the prototype and language code, and to verify that the athlete understood the stimuli correctly.

Using the linguistic code and the developed hardware and software prototypes, we perform the following experimental procedures.

\section{V.1 TEST PROCEDURE 1: ASSESS THE MOST SENSITIVE AREAS OF THE ARMS (LOCATION: SPORTS COURT)}

The purpose of test 1 was to assess the most sensitive areas of the arms for the application of the vibrating commands to gently turn left and right. For this, tests were carried out with 5 athletes and in 3 different positions on the arms, being the shoulder, above the elbow and on the wrist, to verify which place of vibration of 
greater perception for the athlete at the race. As a result, the pulse was chosen, unanimously, by the athletes as the region of greatest perception.

\section{V.2 TEST PROCEDURE 2: ASSESS THE MOST SENSITIVE AREAS IN THE FRONT AND BEHIND (LOCATION: SPORTS COURT)}

In test 2 the objective was to test the areas of greatest sensitivity for the commands that involve vibration in the front and behind the athlete's body. These are the athlete approach commands (commands 4 to 7 ) and a $100 \mathrm{~m}$ advance command. Tests were performed with 5 athletes and in 2 different positions on the front and back of the athletes' body, with the objective of verifying in which place, the vibration was the most noticeable in running. The two positions to perform belt positioning tests with vibrating devices were the waist region and the chest region of the athlete. The location chosen by all 5 athletes was below the chest as shown in Figure 6. It is said that these tests were applied by sending commands from the developed android application to the ESP32 microcontroller.

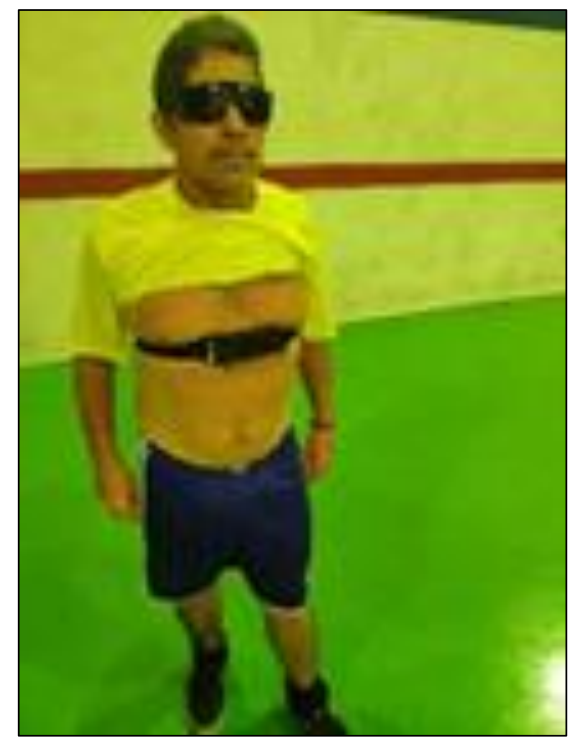

Figure 6: Elastic belt with vibrating devices placed in the athlete's chest position.

Source: Authors, (2021).

\section{V.3 TEST PROCEDURE 3: VERIFY INTERPRETATION OF EACH COMMAND (LOCATION: TRACK)}

The purpose of test 3 was to verify on an athletics track, the individual interpretation of each of the commands of the linguistic code with each of the 5 evaluated athletes. To perform the tests, each of the commands in Table 1 was sent individually to each athlete at the track, and the athlete was checked to identify the information sent. To carry out the verification, the movement performed was observed and the athlete was asked for verbal confirmation regarding the command identification. As a result, $100 \%$ of the tested athletes identified all commands sent after 15 minutes of training. However, for the right and left turn commands, it was difficult for the athletes to determine the degree of the slope, thus having results not so satisfactory with the training time used. It is said that these tests were applied by sending commands, from the application to the ESP32 and by sending the commands to the
ESP01 microcontrollers, placed on the wrists, or vibration motors of the desired position (e.g., chest or back).

\section{V.4 TEST PROCEDURE 4: VERIFY APPROACHING AND DISTANCING COMMANDS (LOCATION: TRACK)}

In test 4, we verified whether the commands for approaching and distancing the athlete ahead (commands 4 and 6) and the approach and distance for the athlete from the back had the variation in vibration force (e.g., increase or decrease) necessary for the athlete perceive the approach or distance. The values used for reducing and increasing the vibration power were, the change from 135 to 150 for the increase, and change from 150 to 135 for the decrease. The tests were carried out with the 5 athletes, for whom commands were applied with power variation of the motor located on the athlete's chest and back and asking for confirmation of the interpretation of the commands by the athletes. As a result of the tests, we found that of the total of 35 commands sent to the 5 athletes, 31 were correctly interpreted. In cases where the command was not interpreted correctly, we verified that the prototype slipped due to the athlete's sweat.

\section{V.5 TEST PROCEDURE 5: CHECK ALL THE COMMANDS (LOCATION: TRACK)}

The purpose of this test was the athlete to test the system presented in this article when running on the track, without a guide and receiving commands passed through the system. As in test procedure 3, athletes had difficulties in knowing the degree of inclination for the controls to gently turn left and right. To overcome this problem, tests were performed to decrease the engines vibration frequency to perform a lower incline, and even then, the problem continued to occur. From there, a training of approximately 5 hours was carried out so that the athletes were able to use properly the developed system. From the training we obtained a satisfactory result, where all 5 athletes managed to complete the 100-, 200- and 400-meters race using, each athlete, 2 lanes of the athletics track.

\section{CONCLUSIONS}

In this article, we present a prototype of hardware and software to guide athletes with visual impairments in athletics competitions. The prototype developed was tested in simulated races on an athletics track, verifying its viability with use by athletes on courses of 100, 200, 300 and $400 \mathrm{~m}$.

We conclude that after the development of a location subsystem using high precision GPS and improvements in the guidance subsystem related to the turn angle on the track, the developed system has the potential to be used in real competitions. The athletes and guides welcomed the prototype and during the tests, the athletes claimed to feel autonomy with the information received by the vibrating devices, as well as praising the fact that they might not be concerned with the synchronization with the guide in the race, focusing on improving the race time.

As a future work, it is also suggested a version of the prototype that makes it possible to choose, via voice commands, a location on a city map so that the developed prototype / device vibrates warning about the directions to be taken on the route selected map. 


\section{AUTHOR'S CONTRIBUTION}

Conceptualization: André Machado.

Methodology: André Machado and Celso Carvalho.

Investigation: André Machado.

Discussion of results: Celso Carvalho and André Machado

Writing Original Draft: Celso Carvalho and André Machado.

Writing - Review and Editing: Celso Carvalho.

Resources: André Machado.

Supervision: Celso Carvalho.

Approval of the final text: Celso Carvalho and André Machado.

\section{ACKNOWLEDGMENTS}

The authors thank the support of Centro de Pesquisa e Desenvolvimento em Tecnologia Eletrônica e da Informação CETELI/UFAM, Graduate Program in Electrical Engineering at the Federal University of Amazonas, Manaus - AM, Coordenação de Aperfeiçoamento de Pessoal de Nível Superior (CAPES), Fundação de Amparo à Pesquisa do Estado do Amazonas (FAPEAM/ProgramaPPP), Fundo Setorial de Infraestrutura (CTINFRA), MCT/CNPQ, SECTI-AM and Amazonas State Government.

\section{REFERENCES}

[1] D. Ferreira, R. Souza, and C. Carvalho. QA-kNN: "Indoor Localization Based on Quartile Analysis and the kNN Classifier for Wireless Networks". Sensors, v. 20, n. 17, pp. 4714, Aug. 2020. DOI:10.3390/s20174714

[2] D. Ferreira, and C. Carvalho. "Localization in Indoor Environments Using Virtualized Three-Dimensional Matrix". ITEGAM-Journal of Engineering and Technology for Industrial Applications (ITEGAM-JETIA), v. 5, n. 18, p. 120-127, Jun. 2019. https://dx.doi.org/10.5935/2447-0228.20190037.

[3] T. De Souza, G. Rodrigues, L. Serrão, R. Macambira, and C. Carvalho. "Residential Smart Plug with Bluetooth Communication". ITEGAM-JETIA, v. 6, n. 21, pp. 20-30. Feb. 2020. https://dx.doi.org/10.5935/2447-0228.20200003.

[4] M. Pieralisi, V. Di Mattia, V. Petrini, A. De Leo, G. Manfredi, P. Russo, L. Scalise, and G. Cerri. "An electromagnetic sensor for the autonomous running of visually impaired and blind athletes (Part I: The fixed infrastructure)". Sensors, v. 17, n. 2, pp. 364, Feb. 2017. DOI: 10.3390/s17020364.

[5] O. Metatla, A. Oldfield, T. Ahmed, A. Vafeas, and S. Miglani. "Voice user interfaces in schools: Co-designing for inclusion with visually-impaired and sighted pupils". In: Proceedings of the 2019 CHI Conference on Human Factors in $\begin{array}{lllll}\text { Computing } & \text { Systems. } & \text { pp. } & 1-15 . & \text { May. }\end{array}$ https://doi.org/10.1145/3290605.3300608.

[6] T. S. Filgueiras, A. C. O. Lima, R. L. Baima, G. T. R. Oka, L. A. Q. Cordovil, and M. P. Bastos. "Vibrotactile sensory substitution on personal navigation: Remotely controlled vibrotactile feedback wearable system to aid visually impaired". In 2016 IEEE International Symposium on Medical Measurements and Applications (MeMeA) pp. 1-5. May. 2016. DOI: 10.1109/MeMeA.2016.7533768.

[7] H. C. Council. "Supporting Children with Sensory Impairment". Routledge, 2016. https://doi.org/10.4324/9781315687940.

[8] P. B. Shull, B. Peter, D. Damian. "Haptic wearables as sensory replacement, sensory augmentation and trainer-a review". Journal of neuroengineering and rehabilitation, v. 12, n. 1, pp. 1-13, Jul. 2015. DOI:10.1186/s12984-015-0055-z

[9] J. Dammeyer, C. Lehane, M. Marschark. "Use of technological aids and interpretation services among children and adults with hearing loss". International journal of audiology, v. 56, n. 10, pp. 740-748, May. 2017. DOI: 10.1080/14992027.2017.1325970.

[10] A. S. Shahriman, M. A. Wahid, S. M. Saad, M. Z. Zain, M. Hussein, Z. Ahmad, M. S. Yaacob, M. Y. Abdullah, and M. Mohamad. "Improving design of piezoelectric braille cell for Braille display devices". Journal of Telecommunication, Electronic and Computer Engineering (JTEC), v. 10, n. 1-14, pp. 107-111, 2018.
[11] A. Carrera, A. Alonso, R. De la Rosa, and E. J. Abril. "Sensing performance of a vibrotactile glove for deaf-blind people". Applied Sciences, v. 7, n. 4, pp. 317 , Mar. 2017. https://doi.org/10.3390/app7040317.

[12] M. Richardson, J. Thar, J. Alvarez, J. Borchers, J. Ward, and G. HamiltonFletcher. "How much spatial information is lost in the sensory substitution process? Comparing visual, tactile, and auditory approaches". Perception, v. 48, n. 11, pp. 1079-1103, Sep. 2019. https://doi.org/10.1177/0301006619873194.

[13] A. Vasquez-Rosati, C. Cordero-Homad. "Proprioceptive Perception: An Emergence of the Interaction of Body and Language". In: Proprioception. IntechOpen, jan. 2021

[14] E. G. Boring. "Sensation and perception in the history of experimental psychology". Appleton-Century, 1942. DOI: 10.5772/intechopen.95461.

[15] K. Aqeel, U. Naveed, F. Fatima, F. Haq, M. Arshad, A. Abbas, M. Nabeel and M. Khurram. "Skin Stroking Haptic Feedback Glove for Assisting Blinds in Navigation". In: 2017 IEEE International Conference on Robotics and Biomimetics (ROBIO). p. 177-182. Dec. 2017. DOI: 10.1109/ROBIO.2017.8324414.

[16] M. Al Zayer, S. Tregillus, J. Bhandari, D. Feil-Seifer, E. Folmer. "Exploring the use of a drone to guide blind runners". In: Proceedings of the 18th International ACM SIGACCESS Conference on Computers and Accessibility. pp. 263-264. Oct. 2016. https://doi.org/10.1145/2982142.2982204

[17] M. Pieralisi, V. Petrini, V. Di Mattia, G. Manfredi, A. De Leo, L. Scalise, P Russo, and G. Cerri. "Design and realization of an electromagnetic guiding system for blind running athletes". Sensors, v. 15, n. 7, p. 16466-16483, Jul. 2015. https://doi.org/10.3390/s150716466.

[18] NodeMCU Documentation. Available online: https://nodemcu.readthedocs.io/en/master (accessed on 14 February 2020). 